\title{
Using Interconnection Network for Constructing Multi-Channels to Integrate and Improve Market of the Tea Industry
}

\author{
Tian-Jia You ${ }^{1, \mathrm{a}}$, Shang-Te Tsai ${ }^{2, \mathrm{~b} *}$, Cheng-Fu Yang ${ }^{3, \mathrm{c}}$ \\ ${ }^{1}$ Department of Economics and Management, Ningde Normal University, China \\ ${ }^{2}$ Department of Chemical and Material Engineering, National University of Kaohsiung, Kaohsiung, Taiwan \\ a14372727@qq.com, bfeilongzz@gmail.com, ${ }^{c}$ cfyang@nuk.edu.tw \\ *Corresponding author: cfeilongzz@gmail.com
}

\begin{abstract}
Recently, the industrialization of tea industry has gotten a great achievement, but the quick investigation of interconnection network give a new challenge in the tea industry, because the selling method is changed. Tea sellers have considered the methods how to expand brand influence, improve the selling model, and promote achievement. In this paper we first analyze the marketing channels of tea industry in Ningde city, one of important principal sites of tea. After that, we proposes using interconnection network for constructing multi-channels, for that we can integrate and improve the marketing of the tea industry in Ningde city. Interconnection network should allow a large number of such transfers to take place concurrently and it can be used to send information to many people at the same time. The paper concludes with a discussion of the significance of interconnection network and its possible future impact on China's sustainable development of tea industry in using e-commerce technology and integration into the global online economy.
\end{abstract}

Keywords: Interconnection network; Multi-channels; Marketing; Tea industry

\section{Introduction}

The tea industry in China remains the largest in the world and China has been dominating in the global tea industry for centuries. As the demand in the global tea market continues to thrive, China's tea industry continues to boom. In recent decades, the tea industry in China has seen rapid growth; mainly driven by the increasing demand in both the domestic and international market [1]. Although tea industry is an important source of income for many Chinese people, its contribution to the country's total gross domestic product (GDP) is considerably less than that of the services and the industry sector. However, the contribution of the tea industry sector in China is remarkably high when compared to those of other developed countries [2]. The fast growing e-commerce culture and technology have changed the consuming culture in China. Tea is one of the importantly industrial crops in China, and tea industry is an important factor to lead the advantage of countryside economy in the East side of Fujian Province. However, over the past two decades because the quick growing is through manufacturing and more recently in the e-commerce sector, the world has witnessed the economic resurgence of China.

Except the problem in china, there are many other problems happening in the world have caused the tea selling becoming difficult in the world. For example, Middle Eastern and Asian tea executives were resolute in the face of diverse challenges at the biennial Global Dubai Tea Forum. It had shown that the globally demand continues to outpace supply with auction prices at lows last seen in 2008. Also, the Civil wars and social unrest continue to weigh heavily on the business of tea. Economic doldrums globally and the depressed Russian and CIS tea markets received a lot of attention [3].

An interconnection network in a parallel machine transfers information from one original source node to any other desired destination nodes. This task should be completed and finished with as small latency as possible. Interconnection network should allow a large number of such transfers to take place concurrently. For that, it can send the information to any desired destination and it is inexpensive as compared to the other marketing channels. Recently, the quick development of Internet adoption rate and a rapidly developing nationwide courier service, China's online retail sales of US $\$ 426$ billion in 2014; and according to market research transaction volumes are forecast to reach US $\$ 1,011$ billion by $2018[4,5]$.

The main market channels of tea for Ningde city.

According to the analysis data, as Figure 1 shows, the tea will consume 5440, 5670, and more than 6000 thousand tons in 2017, 2018, and 2020, and the tae will output 5570, 5770, and also more than 6000 thousand tons in 2017, 2018, and 2020 , respectively. Ningde city has the products of green tea, white tea, and flower tea etc.., which are China people's favorite tea. Especial the tea growth on a high hill or mountain with a sweet smell is one of a brisk sale. The tea traders in Ningde city have found more than twenty thousand tea house and more than ten terminal markets in the China.

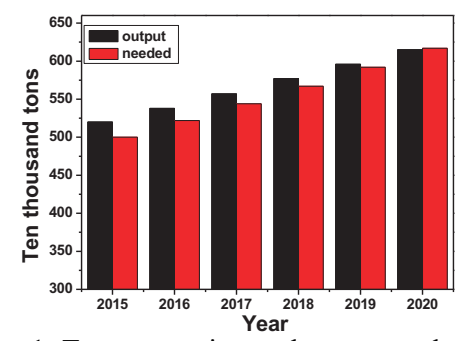

Figure 1: Tea consuming and output analyses.

The studies in the past had found that the selling of tea for Ningde city has the following main market channels:

1. Selling in oversea: In 2016, the China mainland has initiated "The Silk Road Economic Belt and the 21st-Century Maritime Silk Road (The Belt and Road initiative)", Ningde city is along The Belt and Road.

2. Tea wholesale market: this is the traditional channel.

3. Physical store for tea selling: including the tea brand 
name, directly-managed stores, and franchise stores.

4. Tea wholesale store: creating the single brand and selling by the seller, commercial agent, and branch store in the every part of the country.

5. Interconnection network store: business to business (B2B)-Alibaba group and others; Business to consumer (B2C)- Taobao mall (T-mall) and others; Consumer to consumer (C2C)-Taobao mall (T-mall) and others

6. Shopping centre, supermarket: for self-drinking and high standardization of business and political presents.

7. Selling on Wechat and QQ system: creating chatting group on Wechat and QQ system.

As Figure 2 shows, the tea output is more than the tea consuming, find new channel for tea sale will be very important.

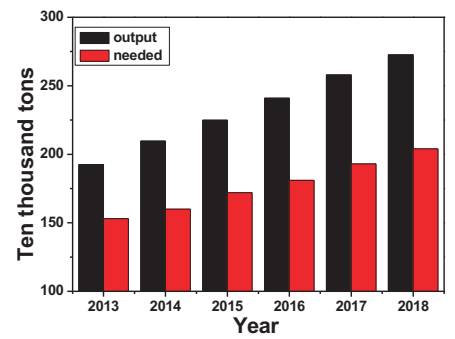

Figure 2: Tea consuming and output analyses in China.

Launched by Alibaba in May 2003, Taobao (T-mall), a leading consumer-to-consumer (C2C) e-marketplace, has defeated international giants of eBay [6], and it becomes China's largest $\mathrm{C} 2 \mathrm{C}$ e-marketplace. T-mall boasts the greatest number of product listings, registered by users, and has the largest transaction volume. The quick development in China's e-commerce has nurtured a consumer-oriented culture in the Interconnection Network, one characterized by frequent visits to e-marketplaces such as Taobao.com, which became the biggest US 'initial public offering' (IPO) in history in 2014. In 2013, more than 500 million registered users and 60 million daily visitors [7].

Because the price-conscious among netizens, many selling channels have been developed and emerged in an endless stream, however, those channels cannot combine to pool efforts forming an attracting brand having the special personality and characteristic. The consumption habit and sense of customers also change with the variation of e-market, but the selling channels have not done any regulations to fit the variation. It means the better selling channels cannot be immutable and frozen and need to take advantage of an opportunity

Influence of interconnection network on the tea selling market

The shock effect of interconnection network has accelerated tea market in Ningde city to the out-of-order condition and even with broader selling channels they do not let tea market forces play their basic role in allocating resources. The special personality and characteristic of consumer behavior and the selling on interconnection network have charged the traditionally physical stores. At the present stage the selling methods have restricted the tea markets growing healthy and sound, the problems are below:

1. The marketing channels are complicated and the tea industries are used to using one method for selling

Now the tea industries are using one or two channels for selling because they are tried to cut down the exploiting and managing cost, and that also cause the products spread out efficiently. Each selling channel has its independence and they are not easy to effectively compromise together. As compared with the Western countries we have found that the selling channels of teat industry have the problems of not materialization, narrow selling, and divergence channels.

\section{The less experiential consumption of tea}

So far, the stylish of consumers has been promoted and they concern on experiential consumption rather than on price. In order to save the site rent expense the physical stores are reduced the area, and the area just can store up the product and sell and it cannot give the consumers having experiential consumption. However, the internet-selling cannot support the cash-and carry and guidance of tea taste for consumers.

3. Consumer behavior becomes personalization

Because of the development of internet consumers can buy tea from different channels, and the consumer behavior becomes personalization. At the first, the online shopping platform can constructed on the interconnection network and the consumers can get the information of tea from different channels at the first moment. Second, the cognition and taste level of consumers have been upgraded, they could never settle for such popular products and start seeking the products fitting their taste and psychology requirements.

4. Channels of internet marketing shock the traditionally physical stores

On 5 March 2015, the Chinese Premier Li Keqiang unveiled China's ambitious Internet-Plan, a strategy really designed to lift the Chinese economy to a new level in the wake of deteriorating returns in traditional industries and a slowing of GDP growth [5]. As being compared with the physical stores, the internet marketing has the advantages of low seeking and managing cost, high work efficiency, and facing more consumers at the same time. Another reason is that the quick development of smart-phones causes the sales volume on internet marketing being larger than on PC. For that, the most physical stores become the center of undergoing an experience and they cannot obtain the sales income, the existence crisis of physical stores becomes more apparent.

Whole thinking of integration all selling channels for the tea industry of Ningde city

Tea is one of the traditional consuming products in China. The tea's quality is difficult to be controlled because of the reasons of the different tea merchants and places of production. Consumers universally express that they cannot but the tea with good quality and at fair price from the mass products. To be against at these problems, many tea merchants try to solve via the platform of interconnection network. How to use electronic commerce (e-commerce) efficiently and create the products with high quality-price ratio and being trusted by the consumers is the neck to break through the tea industry. According to the analysis of depth research report of "2016-2021 the prospect and prediction and the market of China tea industry", the selling channels of tea can be effectively integrated by the platform of interconnection network and can construct a supply chain from the tea plant, 


\section{Recent Developments on Information and Communication Technology (ICT) Engineering- Meen, Yang \& Zhao ISBN: 978-981-14-2136-5}

production, and teahouse to from a joining supply chain. This tea supplier can control the demand of the consumer and regulate their products to match the requirement, and also, the tea supplier will improve their tea quality.

Procedure step to integrate multi-channels for the selling of tea industry

The integration of tea industry of Ningde city is in accordance of the following three steps:

First, we need to confirm the final objective of integration multi-channels of tea industry of Ningde city, which one is the dominant brand, and launch front-end work of integration selling channels. There are many different brands in Ningde city, and we suggest to integrating as the brands of "Tan-Yang" and "Fu-Ding white tea". Also, we suggest inviting the tea industrial and selling specialists to propose the planning and objective of scientific integrating selling, including the study of system, setting up the tea society, and applying the public brand, and protecting the geography mark of brand.

Second, the Ningde city government supports the suggestions of constructing brand and integrating selling, and the tea society and the research institute of industrial tea help to confirm the public brand and construct the product, quality, and technology standards.

Third, the integration principle is unite brand, unite technique, unite standard, unite estimation, and unite propagation, but the each tea industry manages itself. The all tea industries in Ningde city have the same quality and management, but they can sell tea according to their effect sales. All tea in Ningde city has the same quality and technology standards, and Ningde city government sponsor the supports of found and information. They can use the mediums of outdoor advertising, newspaper and magazine, $\mathrm{TV}$, network, and cell phone for their propaganda work.

Integration of multi-channels selling method of tea industry in the micro-view aspect

Marketing usually includes market survey and prediction, analysis of marketing service, study of consumer behavior, product development, lay down price, construction of selling channels, and sales promotion. In the traditional selling the industries are the principal parts, but for the integration of the multi-channels selling the government, industrial association, society, and institute will take flexible advantage of giving scope for each department. The industries will not fight alone and all departments seek unity of marketing challenge together.

As the multi-channels are used for selling, the tea customers can obtain the tea information from the multi-channels, including of friends and platforms of internet stores. This result suggests that customers' consumption behaviors will be influenced from multi-channels. Whenever necessary the tea merchants need to modulate their overall arrangement of product. Based on the selling circumstances and the developments of multi-channels, the tea merchants can use the online to offline (O2O) selling model, it means using selling model of experience firsthand or the channels + social contact, relying on the analysis of big data to establish selling strategy, which can be modified by the times expansion and customer demand. The following five methods can be used to integrate and improve market of the tea industry, and the details for the five methods are described below.

1. Integration of the online and offline resources to achieve the real of $\mathrm{O2O}$ on sale

The Internet technologies have accelerated the globalization of business and drive the pervasive diffusion of e-commerce, and $\mathrm{O} 2 \mathrm{O}$ has become the main method for the large physical enterprise to explore the internet-selling. Because the online shopping lacks face-to-face interaction between buyers and sellers, that will provoke even greater uncertainty about product quality. When the tea merchants select and adopt the $\mathrm{O} 2 \mathrm{O}$, which can achieve online consumption and offline taste or offline taste and online consumption.

When tea merchants manage $\mathrm{O} 2 \mathrm{O}$ selling model, they should start from three different aspects. First, they need constructing the internet platform. They can construct the platform themselves or by renting platform from different e-commerce (for example Taobao), which is dependent on their strategy of development and budget. Second, the consumers can decide buying or not by scanning the two-dimensional bar code. Third, the physical stores support the distribution center, and consumers can choose the delivery store. $\mathrm{O} 2 \mathrm{O}$ selling method can integrate the online and offline resources, it can also have the aids of modern internet and information technologies and can rely on the physical sore, and then can provide the services of multi-channels for consumers.

2. Increasing the selling format of learning through practice and pay attention on the quality

Recently, many times the pesticides are found to be exceeded the prescribed standards. For that the tea franchised shops cannot but must be transformed to investigate the taste shops, and they also devote to improve the tea quality and consumers' taste. For that, the tea merchants are tried to effectively assimilate the elements of relaxation and amusement into the taste shops. In the multi-channels the tea merchants can regulate their managing workings from the certain aspects.

(a) Supporting the consumers examine and return of goods if the consumers find the taste or the quality do not as being anticipated, they can return of tea at the taste store.

(b) Construct the physical stores to be the tea tasting and picking up center. For that, the consumers can taste the tea before they buy and can buy the tea in multi-channels. After the consumers have paid the money, they can pick up tea from the physical stores.

(c) Taste shops can be the after-sales service ensuring centers. If the consumers have question or dissent on the price and manufactured date of their tea, they can appeal in the taste stores. Also, they can seek advices from the taste stores for the making tea and preserving tea.

\section{Exploit the channels of mobile marketing}

From the researches in 2015, people in China having cell phone are more than $90.1 \%$ and the deals on the wireless increased $94.5 \%$, the retail ratio on internet is $56.1 \%$, and the retail ratio on internet will be more than $75 \%$ in 2018 . Because the wireless retail ratio increases every year, tea merchants need to prepare the extension service on the wireless. The wireless is not the duplicate of the $\mathrm{PC}$, for that tea merchants 
have three problems need considering. (a) When the wireless deal platform is constructed, tea merchants need having APP themselves, which is constructed depending on consumers' preference. (b) The selling on wireless platform can use the message or discount model, then we can enhance the contact with consumers. (c) Tea merchants can rely on the cell number website or the mobile social platform to spread on sale.

\section{Investigation of the selling model of mixing channels and social interaction}

Interconnection network has rapid growth, consumers are more and more relying on the information for sharing and recommendation, conflict with the information of commerce poster, and are more favorite with the shopping and social platforms. When tea merchants establish the selling plan, they can attach on the superiority of social platform to attract consumers and then finish the deals. For example, they can construct social team and apply the weibo and wechat ID, they can upgrade the information of company and tea and attract consumers becoming fans. The social team of the tea company can announce the information of sales promotion or hold the competition of interesting tea knowledge. That can attract the consumers and enhance the habit of relying on tea company.

\section{Exact and precise selling of using big data}

The Chinese Government's action plan on the Internet+ ecosystem, which integrates mobile Internet, cloud computing and big data together with the online-to-offline (O2O) strategic alliance of virtual and physical stores, reveals its aspiration toward the development of a consumer orientation in e-commerce activities. Because the quick development in the modern information technology the information browsed by people will be recorded and transferred to database of tea companies. When tea merchants use the $\mathrm{O} 2 \mathrm{O}$ selling model, the physical stores can realize the customers from multi-channels and they can match their requirements. Tea merchants can collect and order the data of customers, and they can establish and launch correct sell with personality. For that, tea companies can save the cost and get effective effect in selling.

Figure 3 and Figure 4 compare selling money and profit of two tea companies in Ningde city, in which company A is used the old selling channel and company B is used the new selling method of multi-channels. These old selling channels have caused the problems of no apparent growing up in selling and no apparent enhancing in profit. As company B used interconnection network for constructing multi-channels for selling tea from 2015, the selling money and profit are apparently improved. These results suggest that using interconnection network for constructing multi-channels for selling is a good method to enhance the selling and profit of tea.

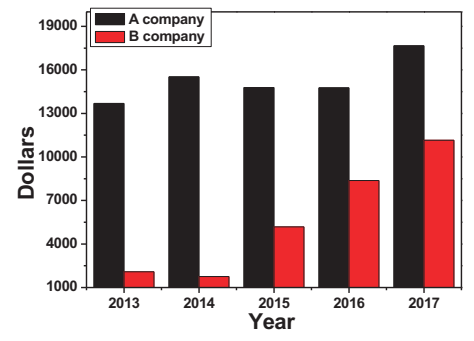

Figure 3: Sale money of two compared companies in China.

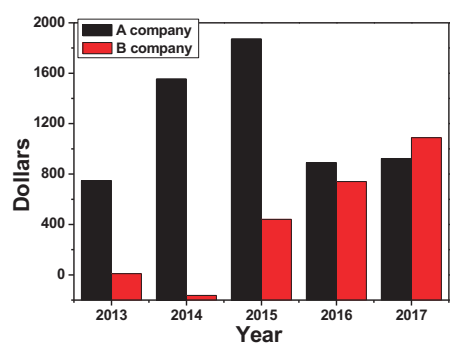

Figure 4: Profit of two compared companies in China.

\section{Conclusion}

In this paper, we propose a new idea, which uses the idea of interconnection network for constructing the multi-channels to integrate and improve market of the tea industry in Ningde city. Tea merchants can past the information to the consumers having a cell phone using the platforms of message, e-mail, and weibo and wechat ID. Consumers can understand the information of their ordering products by multi-channels and they can also enjoy the uniformity consumption experience. For that, tea companies can guarantee the integration of company brand and channel. The behavior and psychology of consumers have been influenced by the interconnection network, those can give the tea company having good chances to precisely match the requirements of customers. Because of the help of big data analysis tea companies can give customers having personality taste and promote more deals.

\section{References}

[1] Nick (2017), "Tea Industry in China: Remains Largest in the World (2017)," available at https://www.bizvibe.com/blog/ tea-industry-china-remains-largest-world/

[2] The Statista, Agriculture (2017), "Tea production in China from 2000 to 2016," available at https://www.statista.com/statistics/ 275639/tea-production-in-china/

[3] D. Bolton (2016), "Global Tea Industry Faces Diverse Challenges," available at http://worldteanews.com/insights/ global- tea-industry-faces-diverse-challenges

[4] eMarketer (2014), "Retail sales worldwide will top \$22 trillion this year ecommerce eclipses $\$ 1.3$ trillion, led by China and US," available at http://www.emarketer.com/Article/Retail-SalesWorldwide-Will-Top-22-Trillion-This-Year/1011765.

[5] M. Cheung and C.F. Yang, "The E-Commerce Revolution: Ensuring Trust and Consumer Rights in China," IEEE-ICICE 2017, November 6 - 11, 2017, Kunming, P.R. China.

[6] iResearch Consulting Group (2011), "2010 China online shopping annual figures," available at http://www.iresearch.com.cn/View/ 131768.html.

[7] TechNode (2013), "How does Taobao use user data?," available at

http://technode.com/2013/06/14/how-does-taobao-uses-user-data 